\title{
The Declining Price Anomaly in Dutch Dutch Rose Auctions
}

\author{
Gerard J. van den Berg* \\ Jan C. van Ours ${ }^{\dagger}$ \\ Menno P. Pradhan $\ddagger$
}

September 29, 2000

\begin{abstract}
We analyze data on sequential Dutch (first price) auctions of roses at a large flower auction in the Netherlands. At a given auction, the roses are homogeneous. The analysis controls for price effects of heterogeneity of roses across auctions. We find that the declining price anomaly in sequential auctions also exists in sequential Dutch auctions.

${ }^{*}$ Department of Economics, Free University Amsterdam, Tinbergen Institute and CEPR.

${ }^{\dagger}$ Department of Economics, Tilburg University, CentER for Economic Research, P.O. Box 90153, 5000 LE Tilburg, The Netherlands and CEPR; vanours@kub.nl.

$\ddagger$ Economic and Social Institute, Free University Amsterdam.
\end{abstract}

Keywords: Sequential auctions, Dutch auctions, declining prices JEL code: D44.

Thanks to the Aalsmeer Flower Auction for the use of their data, helpful suggestions and financial support. Thanks to Orley Ashenfelter, Maarten Cornet, Victor Ginsburgh, Jan Potters, Michael Visser and two anonymous referees for comments and to Baukje Gietema for computational assistance. Also thanks to participants of seminars and workshops in Austin (TU), London (UCL), Berlin (ESEM 98) and Louvain-la-Neuve for comments. 


\section{Introduction}

In symmetric independent private value auctions of a single object with risk neutral bidders, the English (second price) auction has a strategic simplicity. ${ }^{1}$ It is optimal for bidders to reveal their valuation for the object and make bids accordingly. In that case the auction is won by the person with the highest valuation who pays a price equal to the second highest valuation. In a Dutch (first price) auction, this simplicity vanishes. Here winning bidders have to pay their bid. In order to make a profit they shade their bids and bid below their valuation of the object. Somewhat loosely one may state that an English auction is truth revealing, whereas a Dutch auction requires strategic behavior. The simple structure of the one-unit English auction vanishes if two identical objects are auctioned sequentially. Now, in the first round it is optimal for bidders to shade their bids to account for the option value of participating in the subsequent second round (Weber, 1983). Bidders with a higher valuation also have a higher option value. Therefore they shade their bids in the first round by a greater amount than bidders with a lower valuation. As the auction proceeds, the number of bidders decreases. Over the sequence of auctions the number of objects decreases as well. The first has a negative effect on the competition for an object, the second has a positive effect. Both effects cancel out, and prices follow a martingale. As a result, all gains to waiting are arbitraged away and the expected prices in both rounds are the same. The latter result also holds for sequential auctions of more than two objects and does not depend on whether there is an English or a Dutch auction.

This neat theoretical result is not supported by empirical research, which usually finds price declines. Ashenfelter (1989) finds a mild price decrease in sequential auctions of identical units of wine. McAfee and Vincent (1993) also present empirical evidence on sequential wine auctions. They find that, on average, the second unit of wine is sold at a price $1.4 \%$ lower than the price of the first unit. Ginsburgh (1998) uses data on wine auctions in which the auctioneer acts as an agent for bidders who are not present at the auction. He finds price declines, but apparently the absent bidders enter bids which do not fit with the theory. The empirical studies by Ashenfelter and Genesove (1992) (see also Laffont, 1997) and Beggs and Graddy (1997) concern heterogeneous objects. They

\footnotetext{
${ }^{1}$ See McAfee and McMillan, 1987, and Wolfstetter, 1996, for surveys of the auction literature.
} 
also detect price declines. Because of the contradiction between theory and empirical studies, the declining price phenomenon is regarded to be an anomaly. 2,3

This paper contributes to the empirical literature on declining prices. We use data from the Aalsmeer Flower Auction (AFA) on roses to analyze price movements in sequential auctions. AFA is located in The Netherlands and uses a Dutch (descending first-price) auction to sell products. Products are supplied as "lots", which are defined as the total amount of a given product (or article) supplied by a given grower on a given day. A lot consists of a number of fully identical "units" (a unit is a fixed number of flowers, in our case a bucket of roses). The auctioning of the units of a given lot is sequential. Typically, there is more than one round per auction.

Many of the earlier empirical studies of sequential auctions consider the auctioning of objects that are not fully homogeneous, and sometimes the heterogeneous characteristic is unobservable to the researcher. Also, many empirical studies restrict attention to sequential auctions of limited size. Usually, only two or three objects are auctioned sequentially. In contrast, our data concern sequential auctions in which the auctioned lots consist of many units, and each lot is fully homogenous. Our results therefore provide additional insights into the nature of the declining price phenomenon. Another distinguishing feature of the auction we consider is the fact that this is a Dutch (descending first-price) sequential auction, whereas the other empirical studies in the literature deal with

\footnotetext{
${ }^{2} \mathrm{~A}$ few empirical studies find price increases. Donald, Paarsch and Robert (1997) find this in their analysis of timber auctions where bidders are interested in more than one object. These are English auctions of homogeneous objects. Jones, Menezes and Vella (1996) find an increasing price, apparently because the composition of the pool of bidders changes over the sequence of the auction in response to heterogeneity of the objects.

${ }^{3} \mathrm{~A}$ number of recent theoretical studies provide explanations for declining prices in sequential auctions. For example, McAfee and Vincent (1993) require the existence of an unconventional type of risk aversion among the buyers. Branco (1997) assumes that the value of the objects is superadditive for some bidders. Black and De Meza (1993) assume the existence of a "buyer's option" or "parcel option", whereby the winner of the first round has the opportunity to buy the remaining objects at the winning price. Incidentally, Ashenfelter (1989) shows that this does not explain the price decline in the data. Milgrom and Weber (1982) assume that bidders or auctioneers act as agents who are instructed to win an object at any price up to a specified maximum. Von der Fehr (1994) and Menezes and Monteiro (1997) assume that bidders have to pay participation costs. Engelbrecht-Wiggans (1994), Bernhardt and Scoones (1994), and Gale and Hausch (1994) explain the price decline out of heterogeneity of the objects.
} 
second-price sequential auctions.

Most of the earlier studies of sequential auction data examine mean prices at different rounds in a sequential auction, and/or regress the price on the rank number of the corresponding round. However, there may be unobserved determinants of the price that are stochastically related to the rank numbers that are observed in the data. If this is ignored then such methods of inference may provide inconsistent estimates of the magnitude and significance of the price decline. In the empirical analysis we take account of this heterogeneity.

\section{The Aalsmeer Flower Auction}

In this section we give some general statistics concerning the Aalsmeer Flower Auction (AFA), and we provide details of the actual auctioning process. Most of the information on the general statistics is from the Annual Reports of AFA in recent years (see e.g. Bloemenveiling Aalsmeer, 1996a).

AFA is located in Aalsmeer, close to Amsterdam, The Netherlands. It is the largest auction of ornamental plant products (cut flowers, indoor plants, garden plants etc.) in the world. In 1997, about 4.3 billion single flowers, 330 million indoor plants (or houseplants) and 150 million garden plants were traded. The value of the current annual export of flowers equals 4.4 billion guilders (about 2 billion US Dollars). Roses are the most important products that are auctioned at AFA. Together, they amount to $33 \%$ of the total turnover of cut flowers.

The total number of growers who bring products to the auction equals about 7100. The total number of buyers per year equals about 1700 . The dispersion of their shares in total turnover is enormous. On the one hand, about 50 buyers each buy for more than 10 million guilders a year; together this amounts to about $50 \%$ of total turnover. On the other hand, about 725 buyers each buy for less than 0.1 million guilders a year; together this amounts to about $1 \%$ of total turnover. These two extremes basically correspond to big exporting companies and small domestic retail shops, respectively. Obviously some of the large buyers re-sell to other companies (abroad). For cut flowers the dispersion in size is similar. About one third of the buyers each buys for less than 0.05 million guilders per year, which together amounts to only $0.2 \%$ of total turnover in cut flowers.

AFA uses a Dutch auction to sell products. As a starting point, consider the auctioning of a certain "lot" of a homogeneous product. The wall in front of the 
auctioning room contains a large board with a clock and an electronic display of properties of the product to be auctioned (identity of the grower, name of the product, various quality indicators, length of the stem in case of flowers and size of the flower pot in case of plants) as well as properties of the setup of the auction (monetary unit, minimum price). The flowers or plants are transported through the room, and an employee takes a few items from the carriage to show them to the buyers (buyers also have the opportunity to closely examine the flowers some time before the actual auctioning). The auctioneer decides on a starting position for the clock hand which corresponds to an unreasonably high price for the product. He then sets the clock in motion. The value pointed at by the clock hand $^{4}$ drops continuously until a buyer stops the clock by pushing the button in front of him. The value pointed at by the clock hand at that moment is the price to be paid by that buyer for a single item. The buyer then announces how many "units" he wants to buy so there is a "buyer's option" or "parcel option"). A "unit" is defined as a fixed amount of single items (e.g., for a particular type of flower, a unit can be defined as 120 flowers; this definition is fixed for a given product). The identity of the buyer is shown on the electronic display in front of the room. If the number of units he buys falls short of the supplied number of units then the clock is reset to a very high value, and the process restarts for the left-over units. This goes on until the whole lot is sold. So, there is a buyer's option at each round unless only one unit is left. If the hand of the clock passes the minimum price then the remaining lot is destroyed. Every lot is auctioned in this manner.

The minimum price for a given product is fixed throughout the year (at least, for the time periods from which our data are). For the products in our analysis, it equals 10 cents per flower (i.e., per item; a Dutch cent equals 0.01 guilder). The minimum prices are published in an annual code-book which is distributed among buyers and growers (see e.g. Bloemenveiling Aalsmeer, 1996b).

Now let us go back one step and consider how AFA chooses the order of the auctioning of different lots. AFA uses the term "auction group" to denote a group of products with similar features. For example, about 120 auction groups are defined for the 3500 varieties of cut flowers. The sequence in which auction groups appear at the auction is the same on every day. However, the sequence in

\footnotetext{
${ }^{4}$ Actually, the clock is designed as a circle of small lamps each corresponding to a given monetary value, such that a clockwise movement corresponds to a decrease of this value. If the clock is set in motion then consecutive lamps light up sequentially.
} 
which different lots within an auction group appear at the auction is randomized. Note that, by definition, different lots concern different products, if only because the identity of the grower is different.

The AFA buildings contain four auction rooms. The total number of clocks equals 13. These clocks are often used at the same time, so that simultaneous auctions take place within a room. As a result, it is difficult to observe the number of participants at a given auction. A given individual can only participate in one auction, but a given buyer may of course delegate more than one individual to an auction room. The number of seats in an auction room is about 500. The average duration of a single auction (i.e., one transaction) equals just a couple of seconds. The average number of transactions per day at AFA equals about 30,000 .

\section{Empirical analysis}

\subsection{The data set}

We use information on auctions of a particular auction group of roses (AFA code 52 ) for the period June 3 - August 1, 1996. This concerns so-called "large flower" roses, which are relatively expensive and have an exclusive image. We restrict attention to these products because the mandatory minimum purchase quantity does not change during successive rounds of a sequential auction of a given lot, contrary to most other types of roses, where the auctioneer may decide to increase this quantity. According to a survey questionnaire held among buyers at AFA, the latter is the main reason for the observed price declines for the corresponding products (Kalicharan, 1995). By restricting attention to large flower roses, we abstract from this potential cause of declining prices.

In the data period of 44 working days, almost 24,000 lots were auctioned, resulting in about 58,000 transactions (see Table 1). So, on average there were 550 auctions per day and 2.4 transactions per auctioned lot. The average number of units per lot is 6.0 , which illustrates that the buyer's option is frequently exercised. The length of the roses varies from 50 centimeters to over 90 centimeters. On average, the auction price of a rose increases with its length. The color of the roses may be red, brown, green, yellow, orange, purple, white, salmon, etcetera. About 3500 lots contain only 1 unit, but about 500 lots contain 10 units. Obviously some of the growers offer their flowers in small quantities, while others offer 
their flowers in vast quantities. The heterogeneity between the lots is further illustrated by the range of the number of items (i.e., individual roses) per unit. In most cases, this number equals $80,100,120$ or 140 . For about $15 \%$ of the lots this number is outside this range. The average price per rose is 56.8 cents. Note that the minimum price per rose is equal to 10 cents. The highest price is 265 cents (attained in only 1 transaction).

To proceed, we create a subsample in which the range of values of several variables is somewhat restricted. We only consider lots that contain less than 11 units and have a number of items per unit equal to 80, 100, 120 or 140 . Furthermore, the length of roses as measured in $10 \mathrm{~cm}$ is restricted to the range 50-90 $\mathrm{cm}$. In addition, we restrict attention to the 20 products for which the number of transactions during the period of analysis is larger than 1000 . We omit information on lots of which part was destroyed because the price fell below the minimum price (13 lots). Finally, we do not use lots when a minimum purchase quantity larger than 1 was used during the auction (744 observations). As a result, we are left with 14,092 transactions based on 7034 lots. ${ }^{5}$ Table 1 contains summary statistics on the subsample. Note that this subsample contains 3257 lots that were auctioned in 1 transaction, and these cannot be used to study price movements. ${ }^{6}$

Table 2 shows the direction of the price movements between subsequent rounds within the sequential auction of a lot, distinguished by the rank number of the transaction. Considering all transactions, the number of instances where the price increases is slightly below the number of transactions where the price decreases. From the first to the second transaction the price more often increases than decreases. The opposite is the case for most of the subsequent transactions. These results do not provide conclusive evidence of either a price decline or increase. In fact, as Keser and Olson (1996) show, a comparison between the number of increases and decreases is not very informative on the importance of price declines.

\footnotetext{
${ }^{5}$ The restriction to 20 products entails a loss of 29,000 transactions in the data. The restriction to lots of less than 11 units entails an additional loss of about 10,000 transactions.

${ }^{6}$ See Van den Berg, Van Ours and Pradhan (1999) for additional sample characteristics.
} 


\subsection{Price changes in the sequential auction}

A simple regression of the transaction price on the rank number of the transaction can be misleading, for two reasons. To understand the first reason, note that the maximum rank number differs across auctions of different lots. It is plausible that the value of this maximum rank number is not exogenous, because it is an outcome of the behavior of the auction participants and may depend on realized prices earlier on in the sequential auction. Suppose that there is a characteristic of the rose or the auction setup that is unobserved to us but observed by the auction participants. This may affect both the level of the prices within the sequential auction and the number of rounds in the sequential auction. A result of this may be that a relatively high price throughout the sequential auction often goes together with a relatively large number of rounds. This means that in the data, among the realized prices at transactions with large rank numbers, there are relatively many high prices. The regression coefficient of the rank number is then biased upward (i.e., the price declines more than as suggested by the regression estimate) ${ }^{7}$

A second (related) reason for why a simple regression can be misleading is that the price observations for a given sequential auction are typically not independent. There may be unobserved price determinants which affect all realized prices within a sequential auction. In that case, regressions may generate biased results even if the number of rounds would be the same for all sequential auctions.

To advance, we use a fixed effect model for the price as a function of the rank number of the transaction within the sequential auction. This model states that

$$
\log p_{i, j}=\alpha_{i}+\beta_{j} \cdot d_{i, j}+\varepsilon_{i, j}
$$

where $p_{i, j}$ is the price per flower in the transaction with rank number $j=1, \ldots, J_{i}$ in the sequential auction of lot $i=1, \ldots, N$. The lot-specific fixed effect $\alpha_{i}$ captures observed and unobserved heterogeneity between lots. The dummy variable $d_{i, j}$ denotes the rank number of the transaction. The series of $\beta_{j}(j=$ $\left.2, \ldots, \max _{i} J_{i}\right)$ coefficients captures the price change within a lot, relative to the

\footnotetext{
${ }^{7}$ In Van den Berg, Van Ours and Pradhan (1999) we show that this is the case for our data. In a $\log$ price regression, with as explanatory variables: day of the week, lot size, number of items per unit, and length of the flower, we also include the rank number of the transaction. Then the price is estimated to increase with the rank number.
} 
first transaction. Finally, the random variable $\varepsilon_{i, j}$ captures the remaining variation in $p_{i, j}$ and is assumed to be identically and independently distributed across $i$ and $j$.

We eliminate the fixed effect from the model by taking first differences of (1) for pairs of consecutive rounds. In this case, the price change from one transaction to the next is the endogenous variable in a regression. The price change from the $(j-1)^{\text {th }}$ to the $j^{\text {th }}$ round equals

$$
\log \frac{p_{i, j}}{p_{i, j-1}}=\beta_{j}^{*}+\varepsilon_{i, j}^{*}
$$

where $\beta_{j}^{*}=\beta_{j}-\beta_{j-1}$ and $\varepsilon_{i, j}^{*}=\varepsilon_{i, j}-\varepsilon_{i, j-1}$. This estimation approach does not impose a priori that the fixed effect is the same in all rounds within the sequential auction of a lot. An advantage of this is that data on auctions that are finished in say $j_{0}$ rounds do not play a role in the estimation of the price changes in rounds $j>j_{0}$. The equations (2) can be estimated directly by OLS. The estimated coefficient is simply the average observed log price decline.

The estimation approach only uses information on transactions within a sequential auction to estimate the effect of the rank number on the price. The resulting estimates are not affected by the possible biases mentioned at the beginning of the subsection.

The estimated coefficients are given in Table 2. They provide very strong evidence for declining prices within the sequential auction. The point estimate for the first price decline $\beta_{2}^{*}$ is 2.2 percent. The largest price decline is observed from the $3^{\text {rd }}$ to the $4^{\text {th }}$ round (2.8 percent). After that the price declines somewhat less. The price change becomes insignificant after the $6^{\text {th }}$ round.

\subsection{A closer look at the price decline}

We take a closer look at the price decline between two rounds by distinguishing between the effect of the number of units remaining and the rank number of the transaction. To distinguish between the two effects we estimate a regression equation in which we correct both for the rank number of the transaction and for the number of units remaining at the start of each round,

$$
\log \frac{p_{i, j}}{p_{i, j-1}}=\gamma_{1}+\gamma_{2} \cdot(j-2)+\gamma_{3} \cdot(k-2)+v_{i, j} \quad j>1, k>1
$$

where $j$ refers to the rank number of the transaction and $k$ refers to the remaining number of units at the beginning of round $j-1$ (for convenience we suppress the 
index $i$ for $j$ and $k$ ), and $v_{i, j}$ is the error term. For a two-unit lot that is auctioned in two rounds, $j=k=2$, for a three-unit lot where we consider the price change from the first to the second round $j=2, k=3$, for a price change from the second to the third round $j=3, k=2$ etc.. The reference case is a two-unit lot that is auctioned in two rounds. In this case we cannot distinguish between the effect of the rank number of the transaction and the effect of the remaining number of units. The value of $\gamma_{1}$ captures the price change for this case. If we find $\gamma_{2}>0$, then this is evidence that the strongest decline is early on in the auction, whereas if $\gamma_{3}>0$, then this is evidence that the strongest decline is where only a few units remain.

The estimation results ${ }^{8}$ are in Table 3. The first column shows the estimation results if we impose $\gamma_{2}=\gamma_{3}=0$. Then, we measure the average price change over two subsequent auctions within the same lot. It turns out that the average price decline is $2.4 \%$. In the second column we impose $\gamma_{3}=0$, so we only consider the effect of the rank number of the transaction. The resulting estimate of $\gamma_{1}$ is $-2.3 \%$. Furthermore, we find that $\gamma_{2}<0$, indicating that the magnitude of the price decline becomes larger at later rounds. However, the estimate of $\gamma_{2}$ is insignificantly different from zero. The third column shows the estimates if it is imposed that $\gamma_{2}=0$. Now, we find that the coefficient $\gamma_{3}$ is significantly larger than zero, indicating that the fewer the remaining number of units, the larger the price decline. In the fourth column we list the results for the full equation. These agree to those in the second and third column.

We conclude that the declining price is particularly important when going from the first to the second round of a sequential auction, irrespective of the number of units to be auctioned. In addition, at any round, the decline is stronger if the number of units that remain is smaller.

\section{Conclusions}

The data from sequential Dutch Dutch auctions of roses allow us to advance on the understanding of the declining price phenomenon in sequential auctions. First, the products are fully homogeneous. Second, in contrast to previous studies that consider only sequential auctions of limited size, the data contain long sequences of transactions. Third, the data concern Dutch (first price) auctions. We find

\footnotetext{
${ }^{8}$ For these estimates we use lots containing 2-6 units.
} 
price declines in these sequential auctions. Moreover, even in long sequences of auctions there is a declining price. In addition, at any round, the decline is stronger if the number of units that remain is smaller.

A number of theoretical studies provide explanations for declining prices. However, the relation between the models in this literature and the actual setup of the Dutch flower auction is not very close. Virtually all of this literature deals with English auctions or second-price sealed-bid auctions rather than Dutch auctions. In addition, this literature often adopts a basic auction setting with a maximum of two objects to be auctioned. It is a topic for further research to investigate to what extent the predictions of this literature carry over to sequential Dutch auctions with many objects, and, more specifically, to what extent the empirical results in this paper can be reconciled with these predictions. 


\section{References}

Ashenfelter, O. (1989) How Auctions Work for Wine and Art, Journal of Economic Perspectives, 3, 23-36.

Ashenfelter, O. and D. Genesove (1992) Testing for Price Anomalies in RealEstate Auctions, American Economic Review, Papers and proceedings, 80, $501-505$.

Beggs, A. and K. Graddy (1997) Declining Values and the Afternoon Effect: Evidence from Art Auctions, Rand Journal of Economics, 28, 544-565.

Bernhardt, D. and D. Scoones (1994) A Note on Sequential Auctions, American Economic Review, 84, 653-657.

Black, J. and D. de Meza (1993) Systematic Price Differences Between Successive Auctions are no Anomaly, Journal of and Management Strategy, 1, 607-628.

Branco, F. (1997) Sequential Auctions with Synergies: an Example, Economics Letters, 54, 159-163.

Bloemenveiling Aalsmeer (1996a) Annual Report. (in Dutch)

Bloemenveiling Aalsmeer (1996b) Code-booklet 1996. (in Dutch)

Donald, S.G., H.J. Paarsch and J. Robert (1997) Identification, Estimation, and Testing in Empirical Models of Sequential, Ascending-price Auctions with Multi-unit Demand: An Application to Siberian Timber-export Permits, Working Paper, University of Iowa, Iowa City.

Engelbrecht-Wiggans, R. (1994) Sequential Auctions of Stochastically Equivalent Objects, Economics Letters, 44, 87-90.

Gale, I.L. and D.B. Hausch (1994) Bottom Fishing and Declining Prices in Sequential Auctions, Games and Economic Behavior, 15, 318-331.

Ginsburgh, V. (1998) Absentee Bidders and the Declining Price Anomaly in Wine Auctions, Journal of Political Economy, 106, 1302-1319.

Jones, C., Menezes, F.M. and F. Vella (1996) Auction Price Anomalies: Evidence from Wool Auctions in Australia, Working Paper 303, Australian National University. 
Kalicharan, A. (1995) Analysis of Price Behavior at the Flower Auction at Aalsmeer, Working paper, Erasmus University Rotterdam (in Dutch).

Keser, C. and M. Olson (1996) Experimental Examination of the Declining-price Anomaly, in: V. Ginsburgh and P.M. Menger (eds) Economics of the Arts, Selected Essays, Amsterdam, North-Holland.

Laffont, J.J. (1997) Game Theory and Empirical Economics: the Case of Auction Data, European Economic Review, 41, 1-35.

McAfee, R.P. and J. McMillan (1987) Auctions and Bidding, Journal of Economic Literature, 25, 699-738.

McAfee, R.P. and D. Vincent (1993) The Declining Price Anomaly, Journal of Economic Theory, 60, 191-212.

Menezes, F.M. and P.K. Monteiro (1997) Sequential Asymmetric Auctions with Endogenous Participation, Theory and Decision, 43, 187-202.

Milgrom, P. and R. Weber (1982) A Theory of Auctions and Competitive Bidding II, unpublished manuscript, Northwestern University.

Van den Berg, G.J., J.C. van Ours and M.P. Pradhan (1999) Declining Prices in the Sequential Dutch Flower Auction of Roses, Working Paper, Tilburg University, CentER for Economic Research, no. 9952.

Von der Fehr, N.H.M. (1994) Predatory Bidding in Sequential Auctions, Oxford Economic Papers, 46, 345-356.

Weber, R. (1983) Multiple-object Auctions, in: Engelbrecht-Wiggans, R., M. Shubik and R.M. Stark (eds) Auctions, Bidding, and Contracting: Uses and Theory, New York, University Press.

Wolfstetter, E. (1996) Auctions - an Introduction, Journal of Economic Surveys, $10,367-420$. 
Table 1. Descriptive statistics.

\begin{tabular}{|l|l|r|r|r|r|r|r|}
\hline & & \multicolumn{3}{|c|}{ Gross sample } & \multicolumn{3}{|c|}{ Sub-sample } \\
\hline & $\begin{array}{l}\text { unit of } \\
\text { observation }\end{array}$ & $\begin{array}{l}\text { \# } \\
\text { observations }\end{array}$ & mean & std. dev. & $\begin{array}{l}\text { m } \\
\text { observations }\end{array}$ & mean & std. Dev. \\
\hline $\begin{array}{l}\text { price in Dutch cents } \\
\text { cents per rose) }\end{array}$ & transaction & 57981 & 56.80 & 29.58 & 14092 & 60.72 & 25.55 \\
\hline $\begin{array}{l}\text { number of units per } \\
\text { transaction }\end{array}$ & transaction & 57981 & 2.45 & 2.34 & 14092 & 2.08 & 1.47 \\
\hline number of units per lot & lot & 23775 & 5.98 & 5.87 & 7034 & 4.17 & 2.55 \\
\hline $\begin{array}{l}\text { number of transactions } \\
\text { per lot }\end{array}$ & lot & 23775 & 2.44 & 1.88 & 7034 & 2.00 & 1.22 \\
\hline $\begin{array}{l}\text { number of transactions } \\
\text { per lot if }>1\end{array}$ & lot & 13489 & 3.54 & 1.86 & 3777 & 2.87 & 1.07 \\
\hline number of items per unit & unit & 142233 & 120 & 34 & 29320 & 109 & 20 \\
\hline
\end{tabular}

Table 2. Signs of observed price changes, and estimated magnitudes of price changes, by rank number of the transaction.

\begin{tabular}{lrrrrrrrr}
\hline & \multicolumn{7}{c}{ Rank numbers } & \\
\cline { 2 - 6 } & $1 \rightarrow 2$ & $2 \rightarrow 3$ & $3 \rightarrow 4$ & $4 \rightarrow 5$ & $5 \rightarrow 6$ & $6 \rightarrow 7$ & all \\
Sign (\% of total) & & & & & & & \\
Decline & 34 & 42 & 49 & 47 & 42 & 19 & 39 \\
Constant & 20 & 29 & 30 & 31 & 38 & 52 & 24 \\
Increase & 46 & 29 & 22 & 22 & 20 & 30 & 37 \\
& & & & & & & \\
Avg. \% change & -2.2 & -2.6 & -2.8 & -2.7 & -1.7 & -0.7 & -2.8 \\
estimate & $(15.4)$ & $(16.6)$ & $(12.1)$ & $(7.9)$ & $(3.4)$ & $(0.5)$ & $(20.3)$ \\
(t-statistic) & 3777 & 1953 & 867 & 334 & 100 & 27 & 7058 \\
\# observations & & & & & & &
\end{tabular}

Table 3. Estimation results for the effects of the rank number $j$ of the transaction and the number of remaining units $k$ (in \% , t-statistics in parentheses).

\begin{tabular}{|l|r|r|r|r|}
\hline & 1 & 2 & 3 & 4 \\
\hline Constant & -2.41 & -2.32 & -3.13 & -3.12 \\
& $(-25.33)$ & $(-19.52)$ & $(-19.27)$ & $(-16.33)$ \\
\hline$j-2$ & & -0.12 & & -0.01 \\
& & $(-1.21)$ & & $(-0.11)$ \\
\hline$k-2$ & & & 0.24 & 0.24 \\
& & & $(5.44)$ & $(5.30)$ \\
\hline
\end{tabular}

